\title{
ROLE OF FEEDSTOCK TRANSPORT IN THE BALANCE OF PRIMARY PM EMISSIONS IN TWO CASE-STUDIES: RMSW INCINERATION VS. SINTERING PLANT
}

\author{
Simona CIUTA ${ }^{1}$, Marco SCHIAVON ${ }^{2}$, Alessandro CHISTE ${ }^{3}$, Marco RAGAZZI ${ }^{4}$, \\ Elena Cristina RADA ${ }^{5}$, Marco TUBINO ${ }^{6}$, Adrian BADEA $^{7}$, Tiberiu APOSTOL $^{8}$
}

\begin{abstract}
Some preliminary considerations are presented on the role of direct particulate matter emissions vs induced transport emissions for two kinds of plants: incinerator and sintering plant. The developed balances demonstrate that in terms of total amount emitted, the emissions from not optimized transport of raw materials are comparable with the ones from the stacks of the sintering plant. That means it is important to promote initiatives for the adoption of modern engines in the transport system.
\end{abstract}

Keywords: PM, incineration, sintering plant.

\section{Introduction}

One of the main air quality indicators is the particulate matter (PM) concentration at ground level. It is demonstrated that small aerosol particles or particulate matter (as $\mathrm{PM}_{10}$ and $\mathrm{PM}_{2.5}$ ) affect air quality and can have significant effects on human's health [1]. Anomalous exposure to PM can shorten life expectancy, hospital admissions and emergency room visits. For these reasons, various national and international institutions [2,3] have established regulations to reduce PM concentration caused by human activities and to set adequate PM concentration limits.

Assessing air pollution in complex morphologies becomes an important issue in order to implement mitigation measures and limit emissions from the most relevant sources, such as traffic, manufacturing activities, heating and energy production. One of the consequences of the climate is the thermal stratification of the atmosphere within the valley, which makes the dilution of pollutants difficult [4].

\footnotetext{
${ }^{1} \mathrm{PhD}$, Power Engineering Faculty, University POLITEHNICA of Bucharest, Romania

${ }^{2}$ M. Sc., Engineering Faculty Civil and Environmental Dep., University of Trento, Italy

${ }^{3}$ M. Sc., Engineering Faculty Civil and Environmental Dep., University of Trento, Italy

${ }^{4}$ Associate Prof., Engineering Faculty, Civil and Environmental Dep., University of Trento, Italy

${ }^{5}$ Ass. Researcher, Engineering Faculty, Civil and Environmental Dep., University of Trento, Italy

${ }^{6}$ Prof., Engineering Faculty, Civil and Environmental Dep., University of Trento, Italy

${ }^{7}$ Prof. Power Engineering Faculty, University POLITEHNICA of Bucharest, Romania

${ }^{8}$ Prof., Power Engineering Faculty, University POLITEHNICA of Bucharest, Romania
} 
The aim of this study is to evaluate preliminarily some aspects related to the influence of raw material transport on the primary emissions of PM from two plants in which thermal processes take place: a sintering plant and a Residual Municipal Solid Waste (RMSW) incineration plant. In this paper, this two industrial plants are supposed to be situated in a valley in the North of Italy. The total population of the virtual case-study Province is 519,800 [5]. Generated data are not referable to existing and proposed plants.

\section{Materials and methods}

The hypothesized incineration plant will treat 103,000 $\mathrm{t} \mathrm{y}^{-1}$ of RMSW mainly. The efficiency of selective collection in the proposed case-study was supposed to reach the $65 \%$ of the total produced waste in 2013, taking into account an amount of $175 \mathrm{~kg}_{\mathrm{RMSW}} \mathrm{inh}^{-1} \mathrm{y}^{-1}$. This plant will generate a maximum thermal power of $60 \mathrm{MW}$ and will ensure a minimum net electrical efficiency of $23 \%$ [6]. Stack emissions have to comply with the limit values for the regulated pollutants and must be guaranteed lower than $2 \mathrm{mg}_{\mathrm{PM}} \mathrm{Nm}^{-3}$ for this case-study.

In order to obtain the primary emissions for the RMSW incineration plant, it can be considered a flow of waste (F) depending on the number of hours per year of operation. The energy potential of the material entering the incinerator can be related to its Lower Heating Value (LHV) and the inert content (A) can be assessed from the waste characteristics.

The emission factor for the particulate matter can be calculated using the following expression:

$$
e=\frac{A(1-x) \cdot(1-y)}{L H V}\left[\frac{\mathrm{kg}}{\mathrm{kJ}}\right]
$$

Where: $\mathrm{x}$ - degree of retention of ash in the outbreak

$\mathrm{y}-$ particulate matter retention efficiency

LHV - lower heating value

The total content of particulate matter emitted $(c)$ can be determined taking into account the volume factor $\left(\mathrm{F}_{\mathrm{v}}\right)$, which is defined as the ratio of total volume of flue gas and the amount of heat related to the fuel introduced into the boiler:

$$
c=\frac{e}{F_{v}}\left[\frac{m g}{m_{N}^{3}}\right]
$$

The amount of particulate matter can be determined taking into account the following expression:

$$
P M=F \cdot L H V \cdot e\left[\frac{\mathrm{kg}}{\mathrm{h}}\right]
$$

An alternative way can be adopted using a specific flow-rate that can be related to the LHV of the waste, the yearly amount of waste burnt and the concentration at the stack. 
Concerning the virtual sintering plant, raw materials $\left(530,000 \mathrm{t} \mathrm{y}^{-1}\right)$ for this plant are principally ferrous wastes which arrive through heavy vehicles from several points of the region. The final products are billets and bars of iron.

The emissions into the atmosphere from the plant can be primary or secondary. The first ones come from the raw material processing into the furnace and from the refining furnace. The second ones come from other operations into the plant (spillage, ladle transport operation, etc.) and are called diffuse emissions.

The emission treatment is characterized by two lines: one for the primary emissions and a part of the secondary, and one only for the secondary emissions. The two lines are connected with two different chimneys called L1 (first line) and L2 (second line).

Emission values of PM at the stacks and flow-rates are supposed to be available on-line allowing the assessment of the PM emission flows (expressed in $\left.\mathrm{mg} \mathrm{h}^{-1}\right)$.

For both the plants, in order to calculate the PM emissions related to the systems of road transportation, an emission model (COPERT 4) was used and adapted for this cases study. The COPERT 4 algorithm is part of the EMEP/CORINAIR emission inventory guidebook [7]. This methodology has been developed by EEA within the European Topic Centre on Air and Climate Change (ETC/ACC) activities, with the intention of providing a set of tools for the compilation of emission inventories to the European Countries [7].

The COPERT algorithm estimates emissions of all the main pollutants $\left(\mathrm{CO}, \mathrm{NO}_{\mathrm{x}}, \mathrm{VOC}, \mathrm{PM}, \mathrm{NH}_{3}, \mathrm{SO}_{2}\right.$, heavy metals) as well as greenhouse gases $\left(\mathrm{CO}_{2}\right.$, $\mathrm{N}_{2} \mathrm{O}, \mathrm{CH}_{4}$ ) [7]. These pollutants can be divided into four main groups:

- pollutants whose a detailed methodology for the calculation of the emission factors exists $\left(\mathrm{CO}, \mathrm{NO}_{\mathrm{x}}, \mathrm{VOC}, \mathrm{CH}_{4}, \mathrm{PM}\right)$;

- compounds whose the emission factors are calculated according to the fuel consumption, falling within the second group $\left(\mathrm{CO}_{2}, \mathrm{SO}_{2}\right.$ and heavy metals);

- pollutants whose a simplified methodology is applied, since detailed studies are not available $\left(\mathrm{NH}_{3}, \mathrm{~N}_{2} \mathrm{O}\right.$, PAHs, dioxins and furans);

- profiles of alkanes, alkenes, alkynes, ketones, aldehydes, aromatics and cycloalkanes, derived as fractions of the total NMVOCs [7].

For each pollutant, the algorithm calculates the emission factors (expressed in $\mathrm{g} \mathrm{km}^{-1}$ vehic ${ }^{-1}$ ) relative to specific vehicle classes which the vehicles belong to.

To apply the model, it was necessary to evaluate the vehicle fluxes for the two considered scenarios. A different approach was used to estimate the fluxes of heavy duty vehicles that deliver raw material to the plants.

The delivery of waste to the incineration plant will be provided by a system of road transportation, which will be based on the use of heavy vehicles. 
The typical journey of a vehicle starts in a collection centre, where the truck loads bulky waste, residual waste and scraps from the separate waste collection; later the truck moves to the incineration plant, unloads the waste and comes back empty to the original collection centre. The Province is divided into eleven districts (numbered from $\mathrm{C} 1$ to $\mathrm{C} 11$ ), plus two districts represented by the two main cities ( $\mathrm{C} 12$ and $\mathrm{C} 13)$. In the case of incineration plant, an analysis of the transportation system organization was proposed taking into account that almost all districts will have their own collection centers, where trucks load bulky and residual waste and move to the incineration plant. The frequency of journeys from each collection center depends on the amount of deposited waste, that has been evaluated on the basis of the catchment area of the districts, the estimated evolution of the population in the future years and the decrease of waste production.

Since all the routes between the collection centers and the incineration plant are long itineraries and extra-urban paths, the effects of slowdowns and accelerations (which are typical for urban routes) can be neglected as a first approximation. Consequently, the average speed approach was adopted. The slope effects were taken into account, since every route does not follow a flat pathway (excepted for districts $\mathrm{C} 4, \mathrm{C} 5$ and the district located in the bottom of the valley). Besides the road gradient itself, slope correction factors for heavy vehicles depend on the COPERT vehicle class, depending on the vehicle mass, since the classification for heavy vehicles is based on the gross weight. Hence, different load conditions lead to different correction factors. Moreover, slope correction factors for the same vehicle class are not merely equal in modulus and opposite in sign for a round journey. Consequently, when dealing with non-flat routes, slope effects should not be neglected.

In addition, in order to evaluate the positive effects of the latest emission standards on the decrease of the emitted pollutants, both EURO 1 and EURO 5 heavy vehicles were considered in this study. Since this calculation is based on the average speed approach, a mean speed of $50 \mathrm{~km} \mathrm{~h}^{-1}$ was adopted, both for the outward and for the return journey.

The transportation from the collection centers to the incinerator will take place by means of 26 tons heavy vehicles (with tare of $10 \mathrm{t}$ and load capacity of $16 \mathrm{t}$ ). For those districts without any collection centre, the transportation will be made by 12 tons heavy vehicles (with tare of $4 \mathrm{t}$ and load capacity of $8 \mathrm{t}$ ). For these two districts the delivery of waste to the plant was assumed that will be carried out directly at the end of the collection service of RMSW from the bins located in the territory.

According to the COPERT classification, in the case of the sintering plant, the transportation vehicle classes which the assumed trucks belong to are those for heavy vehicles greater than $32 \mathrm{t}$ (for the outward journey) and the heavy 
vehicles with a weight between $16 \mathrm{t}$ and $32 \mathrm{t}$ (for the return journey). Considering the maximum mass of material the trucks can be loaded is $30 \mathrm{t}$ (which is the difference between the gross weight and the tare of each vehicle) and since the amount of raw material entering the plant is $530,000 \mathrm{t} \mathrm{y}^{-1}$, the number of journeys to transport raw materials to the sintering plant during one year is 17,667 according to this virtual scenario.

In the case of sintering plant, it was assumed that the trucks arrive to the sintering plant from three different points of the region, with different distances and road slopes.

- the first one is $24 \mathrm{~km}$ long with a positive slope of 3\%o (first path),

- the second one is $60 \mathrm{~km}$ long with a positive slope of $3 \%$ (second path),

- the third one is $89 \mathrm{~km}$ long with a positive slope of 7\%o (third path).

The slope is always positive for each path, this means that for the outward journey the road is uphill on average for each path. Moreover it was assumed that the $50 \%$ of the trucks follow the second path, $25 \%$ of them follow the first one and $25 \%$ the third one.

For the considered vehicle classes, COPERT provides the mass of PM emitted for unit of time (1 year in this case) and length $(\mathrm{km})$. In this way, the PM emission values for each path and class were obtained, in term of $\mathrm{kg} \mathrm{y}^{-1} \mathrm{~km}^{-1}$. The calculated PM emission values were multiplied by the length of the respective routes and the total emission values obtained for the outward and the return journeys (expressed in $\mathrm{kg} \mathrm{y}^{-1}$ ) along each path were added up.

Similarly to what performed for the waste transportation system, this procedure was conducted considering both EURO 1 and EURO 5 vehicles. Moreover, in analogy with the previous case study, since the journeys take place on sloping routes, slope correction factors were introduced to consider the effect of road gradient on the emissions. Finally, since all routes to the sintering plant are long itineraries and extra-urban paths, the average speed approach was adopted, as for the case of the incineration plant.

To make a comparison between transportation and primary emissions from the sintering plant, it is necessary to obtain the number of heavy vehicles for the transport of raw material, the covered distance and the PM emission values from the stack of the plant.

\section{Results}

In the case of the RMSW incineration plant, emissions from road transport are a small part of the total emissions, as the first ones remain at least one order of magnitude below the latter as explained below. The lowest emissions are achieved when considering EURO 5 vehicles instead of EURO 1. In fact, PM emissions of the latter are almost five times higher than those related to EURO 5 
trucks (Table 1). Considering stack emissions, assuming a specific flow-rate as $7.5 \mathrm{Nm}^{3} / \mathrm{kg}_{\text {RMSW }}$, an emission of PM of about $1,545 \mathrm{~kg}$ (or less) on yearly basis can be assessed from the second method of calculation (preferred thanks to its simplicity). That value confirms the difference in order of magnitudes between stack and transport emissions.

Table 1

Annual PM emission values related to the road transportation system of the incineration plant, calculated for the two scenarios (with EURO 1 and EURO 5 heavy vehicles)

\begin{tabular}{|c|c|c|c|c|c|}
\hline \multirow[b]{2}{*}{ District } & \multirow{2}{*}{$\begin{array}{l}\text { Distance } \\
\text { from the } \\
\text { plant } \\
{[\mathrm{km}]}\end{array}$} & \multirow[b]{2}{*}{$\begin{array}{l}\text { Average } \\
\text { slope }[\%]\end{array}$} & \multirow{2}{*}{$\begin{array}{l}\text { Mean annual mileage } \\
\text { (outward journey } \\
\text { only) }\left[\mathrm{km} \mathrm{y}^{-1}\right]\end{array}$} & \multicolumn{2}{|c|}{ Annual PM emissions $\left[\mathrm{kg} \mathrm{y}^{-1}\right]$} \\
\hline & & & & $\begin{array}{l}\text { EURO } 1 \\
\text { vehicles }\end{array}$ & $\begin{array}{l}\text { EURO } 5 \\
\text { vehicles }\end{array}$ \\
\hline $\mathrm{C} 1$ & 70 & 1.1 & 7,749 & 6.769 & 1.636 \\
\hline $\mathrm{C} 2$ & 100 & 0.5 & 7,774 & 6.791 & 1.642 \\
\hline $\mathrm{C} 3$ & 44 & 0.5 & 7,285 & 6.364 & 1.538 \\
\hline $\mathrm{C} 6$ e $\mathrm{C} 7$ & 38 & 0.8 & 15,908 & 13.897 & 3.360 \\
\hline $\mathrm{C} 8$ & 45 & 1.0 & 19,370 & 16.921 & 4.091 \\
\hline C9 & 51 & -0.2 & 28,276 & 28.349 & 4.664 \\
\hline $\mathrm{C} 10$ and $\mathrm{C} 12$ & 40 & -0.1 & 27,255 & 27.325 & 4.496 \\
\hline $\mathrm{C} 11$ & 97 & 1.2 & 16,204 & 14.155 & 3.422 \\
\hline $\mathrm{C} 4, \mathrm{C} 5$ and $\mathrm{C} 13$ & - & 0.0 & 54,489 & 30.031 & 8.565 \\
\hline & & & TOTAL & 150.603 & 33.413 \\
\hline
\end{tabular}

For the case of the sintering plant, average values of concentration and flow can be calculated starting from on-line data available in the sector: resulting data are presented in Table 2, in order to finally obtain PM emission values.

To complete the calculation, the number of working hours per year for the sintering plant is needed: it was supposed that plant works in the average 16.5 hours in a day (in the average) and 335 days in a year.

The average values of concentration, flow and the calculated annual PM emissions are presented in Table 2.

Table 2

Average values of PM concentration assumed at chimney level, flow-rate and PM emission

\begin{tabular}{|c|c|c|}
\hline & L1 & $\mathrm{L} 2$ \\
\hline PM concentration $\left[\mathrm{mg} \mathrm{Nm}^{-3}\right]$ & 0.37 & 0.19 \\
\hline Flow $\left[\mathrm{Nm}^{3} \mathrm{~h}^{-1}\right]$ & 553,856 & 691,350 \\
\hline PM emission $\left[\mathrm{mg} \mathrm{h}^{-1}\right]$ & 204,927 & 131,357 \\
\hline PM emission $\left[\mathrm{kg} \mathrm{y}^{-1}\right]$ & 1,133 & 726 \\
\hline Total PM emissions $\left[\mathrm{kg} \mathrm{y}^{-1}\right]$ & \multicolumn{2}{|c|}{1,859} \\
\hline
\end{tabular}

The final results of the emission calculation related to the sintering plant transportation system are shown in Table 3 . In case of old heavy vehicles the contribution of transportation can be comparable with the one of PM from the stacks. 
Annual PM emission values related to the road transportation system of the sintering plant, calculated for the two scenarios (with EURO 1 and EURO 5 heavy vehicles)

\begin{tabular}{|c|c|c|c|}
\cline { 3 - 3 } \multicolumn{2}{c|}{} & \multicolumn{2}{|c|}{ Annual PM emissions [kg y $\left.{ }^{-1}\right]$} \\
\cline { 3 - 4 } & Outward journey & 57.63 & EURO 5 vehicles \\
\cline { 2 - 4 } First Path & Return Journey & 26.16 & 2.93 \\
\hline \multirow{2}{*}{ Second Path } & Outward journey & 288.15 & 7.55 \\
\cline { 2 - 4 } & Return Journey & 130.82 & 14.63 \\
\hline \multirow{2}{*}{ Third Path } & Outward journey & 213.71 & 10.64 \\
\cline { 2 - 4 } & Return Journey & 97.02 & 4.92 \\
\hline \multicolumn{2}{|c|}{ TOTAL } & 813.50 & 41.29 \\
\hline
\end{tabular}

\section{Conclusions}

In conclusion an important difference emerges between the emissions related to EURO 1 and EURO 5 trucks used to simulate the transportation system. Due to the technological progresses made in the last years, EURO 5 trucks emit twenty times less PM compared to EURO 1 trucks.

In case of sintering plants, EURO 1 trucks produce emissions comparable with those released from the chimneys. Hence, at regional scale, road transport can play an important role within the emissive balance. It must be noted that only transportation of metallic minerals were considered in this study. As obvious, several kinds of raw materials are needed for the production of steel billets and bars, such as lime, oxygen, nitrogen, coal dust, oil, gas and refractory materials. A deeper analysis could generate additional interesting information. Furthermore, transport related emissions could be higher when going beyond a regional scale analysis. In fact, if the complete paths from the origin of raw materials to the plant were taken into account, the produced emissions would probably be higher than those assessed.

As a consequence, solutions for lowering the emissions from transport related to the industrial activity like the one analyzed should be promoted.

PM emissions from transport seems to play a secondary role in case of incineration when compared with stack emissions

\section{R E F E R E N C E S}

[1]. B. Brunekreef, S. Holgate, “Air pollution and health", in The Lancet, vol.360/9341, 2002, pp. 1233-1242.

[2]. European Community, "Council Directive 1999/39/EC of 22 April 1999 regulating to limit values for sulphur dioxide, nitrogen dioxide and oxides of nitrogen, particulate matter and lead in ambient air", in Official Journal of the European Communities, L163, 1999, pp. 41-60. 
[3]. European Community, "Council Directive 2008/50/EC, on ambient air quality and cleaner air for Europe". In Official Journal of the European Communities, L152, 2008, 1.

[4]. D. Heimann, M. de Franceschi, S. Emeis, P. Lercher, P. Seibert, 2007. "Air Pollution, Traffic Noise and Related Health Effects in the Alpine Space - A Guide for Authorities and Consulters. ALPNAP comprehensive report", Università degli Studi di Trento, Dipartimento di Ingegneria Civile e Ambientale, Trento, Italy, pp. 335.

[5]. ISTAT, 2011. http://demo.istat.it/bil2008/index.html

[6]. F. Barbone, F. Brevi, U. Ghezzi, M. Ragazzi, A. Ventura, 2009. "Concessione di lavori per la progettazione, realizzazione e gestione dell'impianto di combustione o altro trattamento termico con recupero energetico per rifiuti urbani e speciali assimilabili in località Ischia Podetti, nel Comune di Trento - Studio di Fattibilità", Provincia Autonoma di Trento, Comune di Trento, Italy, pp. 226.

[7]. European Environmental Agency, "EMEP/CORINAIR Emission Inventory Guidebook 2007”, Technical Report, no. 16, 2007, Bruxelles. 